\title{
Noves aportacions al coneixement de la flora al·lòctona de la comarca del Baix Llobregat (Catalunya, Espanya)
}

\author{
H. ÁLVAREZ¹, N. IBÁÑEZ² \& C. GÓMEZ-BELLVER ${ }^{3}$ \\ ${ }^{1}$ Departament d'Agricultura, Ramaderia, Pesca, Alimentació i Medi Natural, c. Tints, 13, ES-08830 Sant Boi de Llobregat, \\ Espanya \\ ${ }^{2}$ Institut Botànic de Barcelona (IBB-CSIC-ICUB), pg. del Migdia, s/n, ES-08038 Barcelona, Espanya \\ ${ }^{3}$ Dept. Biologia Vegetal, Facultat de Biologia, Universitat de Barcelona, av. Diagonal, 643, ES-08028 Barcelona, Espanya
}

Autor per a correspondència: H. Álvarez (hilari.alvarez@gmail.com)

Editor: L. Sáez

Rebut 28 juliol 2015; acceptat 24 setembre 2015.

publicat on line: 31 agost 2016

\begin{abstract}
New contributions to the knowledge of the alien flora in Baix Llobregat county (Catalonia, Spain). - We provide new records of 17 exotic plants in the Baix Llobregat region observed between the years 2011 and 2014. Two species are the first records for Europe: Acacia rostellifera Benth. and Trichloris crinita (Lag.) Parodi; two are new plants for the Iberian Peninsula: Bouteloua dactyloides (Nutt.) Columbus and Nassella tenuissima (Trin.) Barkworth; three are recorded by their first time in Catalonia: Atriplex semibaccata R. Br., Oenothera speciosa Nutt. and Verbena incompta P. W. Michael; five correspond to first records in Baix Llobregat: Parkinsonia aculeata L., Phacelia tanacetifolia Benth., Physalis peruviana L., Salpichroa origanifolia (Lam.) Baill. and Verbena brasiliensis Vell. The remaining species are very rare in the studied area: Abutilon grandifolium (Willd.) Sweet, Asperugo procumbens L., Eclipta prostrata (L.) L. and Oenothera indecora Cambess.
\end{abstract}

Key words: Baix Llobregat; Catalonia; introduced plant; naturalized; non-native.

\section{Resumen}

Nuevas aportaciones al conocimiento de la flora alóctona de la comarca del Baix Llobregat (Cataluña, Espa$\tilde{\mathrm{N} A}$ ).- En el presente trabajo aportamos datos sobre la presencia de 17 plantas alóctonas encontradas en la comarca del Baix Llobregat durante el período 2011-2014. Son primeras citas para Europa: Acacia rostellifera Benth. y Trichloris crinita (Lag.) Parodi. Son nuevas especies para la península ibérica: Bouteloua dactyloides (Nutt.) Columbus y Nassella tenuissima (Trin.) Barkworth. Son novedad para Cataluña: Atriplex semibaccata R. Br., Oenothera speciosa Nutt. y Verbena incompta P. W. Michael. Son novedad comarcal: Parkinsonia aculeata L., Phacelia tanacetifolia Benth., Physalis peruviana L., Salpichroa origanifolia (Lam.) Baill. y Verbena brasiliensis Vell. Las especies restantes son muy raras en el territorio estudiado: Abutilon grandifolium (Willd.) Sweet, Asperugo procumbens L., Eclipta prostrata (L.) L. y Oenothera indecora Cambess.

Palabras clave: alóctonas; Baix Llobregat; Cataluña; introducida; naturalizada.

\section{Resum}

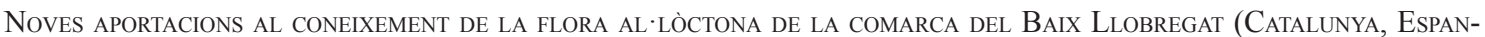
YA).- En aquest treball aportem dades sobre la presència de 17 plantes al·lòctones trobades a la comarca del Baix Llobregat durant el període 2011-2014. Són primeres cites per a Europa: Acacia rostellifera Benth. i Trichloris crinita (Lag.) Parodi. Són noves espècies per a la península Ibèrica: Bouteloua dactyloides (Nutt.) Columbus i Nassella tenuissima (Trin.) Barkworth. Són novetat per a Catalunya: Atriplex semibaccata R. Br., Oenothera speciosa Nutt. i Verbena incompta P. W. Michael. Com a novetat comarcal: Parkinsonia aculeata L., Phacelia tanacetifolia Benth., Physalis peruviana L., Salpichroa origanifolia (Lam.) Baill. i Verbena brasiliensis Vell. Les espècies restants són molt rares en el territori estudiat: Abutilon grandifolium (Willd.) Sweet, Asperugo procumbens L., Eclipta prostrata (L.) L. i Oenothera indecora Cambess.

Paraules clau: al·lòctones; Baix Llobregat; Catalunya; introduïda; naturalitzada. 
Cómo citar este artículo / Citation

Álvarez, H., Ibáñez, N. \& Gómez-Bellver, C. 2016. Noves aportacions al coneixement de la flora al·lòctona de la comarca del Baix Llobregat (Catalunya, Espanya). Collectanea Botanica 35: e007. doi: http://dx.doi.org/10.3989/collectbot.2016.v35.007

Copyright

(C) 2016 CSIC. This is an open-access article distributed under the terms of the Creative Commons Attribution License (CC BY) Spain 3.0.

\section{INTRODUCCIÓ}

La flora vascular del Baix Llobregat ha estat estudiada des del punt de vista botànic des de fa molt temps. Cal destacar les primeres exploracions portades a terme al Prat del Llobregat per la família Salvador (Ibáñez, 2006: 33), la monografia de Bolòs (1950) i les publicacions del butlletí naturalista del delta del Llobregat Spartina (1994-2006).

L'àrea del Baix Llobregat pateix el creixent augment de plantes introduïdes. Aquest fenomen està afavorit per les característiques geomorfològiques de la comarca (proximitat al mar, presència vertebradora del riu Llobregat, clima mediterrani) i per la gran densitat de població humana que acull.

Els estudis de Casasayas (1989) i els més recents d'Andreu et al. (2012) i Andreu \& Pino (2013) constitueixen els treballs de referència sobre les plantes al-lòctones a Catalunya. Diverses campanyes botàniques recents a la zona del Baix Llobregat han detectat una quantitat notable d'espècies no incloses en els esmentats estudis.

En aquest treball donem a conèixer algunes novetats $i$ algunes plantes rares en aquest territori.

\section{MATERIAL I MÈTODES}

Hem realitzat un seguiment de les principals àrees amb vegetació ruderal i arvense associada a vores de rieres, rodalies de zones urbanes i de cultius, a vies de comunicació $i$ altres infraestructures de la part baixa de la comarca.

Els tàxons es presenten agrupats per novetats a diversos nivells (continental, peninsular, autonòmic i comarcal). Dins de cada grup s'ordenen en ordre alfabètic. En cada cas s'indica: el nom científic, la família, el grau de naturalització (seguim la proposta d'Andreu et al., 2012), la valoració de novetat per a la zona, les localitats i els plecs testimoni de les troballes amb l'enumeració de l'herbari on estan dipositats, una breu explicació de l'origen i característiques importants del tàxon, detalls sobre la seva distribució secundària $i$, finalment, informació de la presència actual a la comarca.

Els noms de les famílies, subfamílies, gèneres i epítets específics i subespecífics es basen en Angiosperm Phylogeny Website (Stevens, 2001-). Els autors, els anys i el lloc de publicació dels tàxons segueixen els indicats a The International Plant Names Index (IPNI, 2012). Les localitzacions geogràfiques fan referència a la quadrícula UTM d'1 km de costat (zona 31T), datum ETRS89.

\section{RESULTATS}

\section{Novetats a Europa}

Acacia rostellifera Benth. in London J. Bot. 1: 356 (1842) (Fig. 1) (Fabaceae, subfam. Mimosoideae).

Adventícia.

Espanya, Barcelona, Baix Llobregat: Viladecans, Ca l'Alemany, DF1872, 3,5 m, 09.04.2013, H. Álvarez (BC 878851, BCN 111735); ibid., 20.06.2013, H. Álvarez (BC 878852, BCN 111734).

Representa la primera cita d'aquest tàxon en territori europeu (DAISIE, 2013). No tenim constància de la seva utilització com a planta ornamental a casa nostra. Hem comprovat que no és present en la col·lecció del Jardí Botànic de Barcelona ni tampoc en els principals centres de jardineria propers. Tot $\mathrm{i}$ així és possible que provingui d'exemplars conreats. A Europa trobem amb el mateix nom específic, però amb autor diferent, Acacia rostellifera sensu auct. En realitat correspon a una altra espècie, $A$. retinodes Schltdl. (ILDIS, 2013). És un arbust o petit arbre propi de les zones costeres del sud-oest d'Austràlia. Hem localitzat dos exemplars separats per pocs metres de distància, situats en un erm ruderal dominat majoritàriament per Piptatherum miliaceum (L.) Coss. 


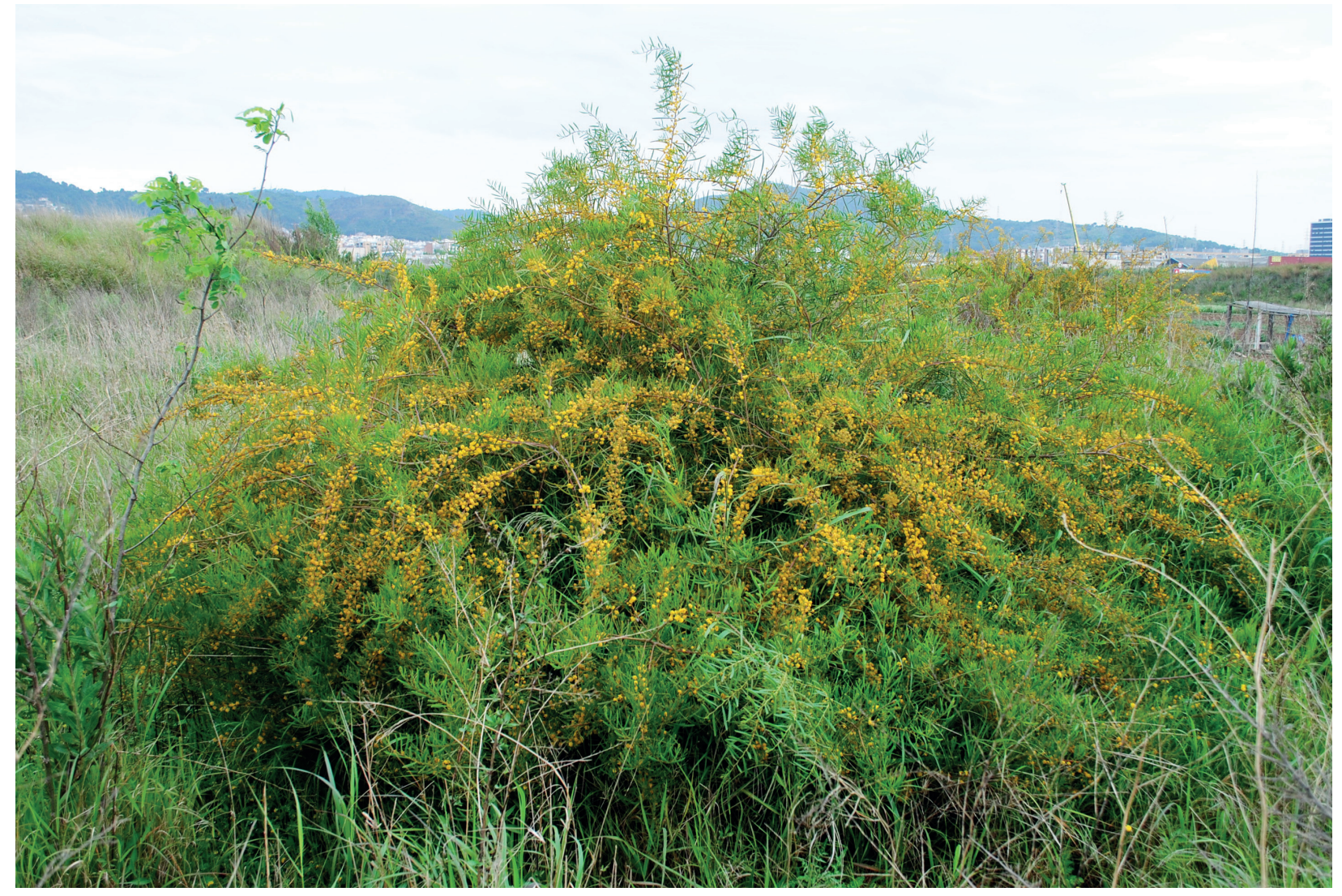

Figura 1. Acacia rostellifera Benth.

Hem dipositat llavors (recol·lectades el 10.07.2014) al banc de germoplasma del Jardí Botànic de Barcelona, amb número de registre 4065JBB.

Trichloris crinita (Lag.) Parodi in Revista Argent. Agron. 14(1): 63 (1947) (Fig. 2) (Poaceae).

Adventícia.

Espanya, Barcelona, Baix Llobregat: Viladecans, Les Maletes, DF1873, $11 \mathrm{~m}, 13.10 .2011, H$. Álvarez (BC 877314, BCN 91848); ibid., 22.12.2011, H. Álvarez (BC 877315, BCN 91849).

El gènere Trichloris Fourn. és nadiu del continent americà, $i$ es distribueix per les regions temperades $i$ càlides, des del sud dels Estats Units fins l'Argentina (Parodi, 1919). Està representat per dues espècies: Trichloris crinita i T. pluriflora Fourn. Trichloris crinita té una distribució disjunta (Peterson et al., 2001), amb poblacions a l'hemisferi austral (Argentina, Bolívia, Brasil, Xile, Paraguai, Perú i Uruguai) i unes altres a l'hemisferi boreal (sud dels Estats Units d'Amèrica i nord de Mèxic). Viu en terrenys argilosos de textura fina, arenosos, salins o en terrenys remoguts. Forma extenses praderies naturals en ambients semiàrids de l'anomenat Monte i està considerada com a planta farratgera de bona qualitat per al bestiar (Giorgetti et al., 1997). Aquesta espècie no apareix recollida en síntesis i compilacions de flora europea (Tutin et al., 1980; DAISIE, 2013).

Hem localitzat $T$. crinita en un ambient periurbà, en un talús de la carretera B-204 al costat de la C-32 que limita amb el parc agrari. La població presenta una bona vitalitat. Durant els tres anys que hem observat la població aquesta no ha crescut. Pensem que la introducció ha estat fortuïta, provinent d'alguna mercaderia.

\section{Novetats a la península Ibèrica}

Bouteloua dactyloides (Nutt.) Columbus in Aliso 18(1): 63 (1999) (Poaceae).

Adventícia.

Espanya, Barcelona, Baix Llobregat: Sant Vicenç dels Horts, riera de Torrelles, erm ruderal sec, 


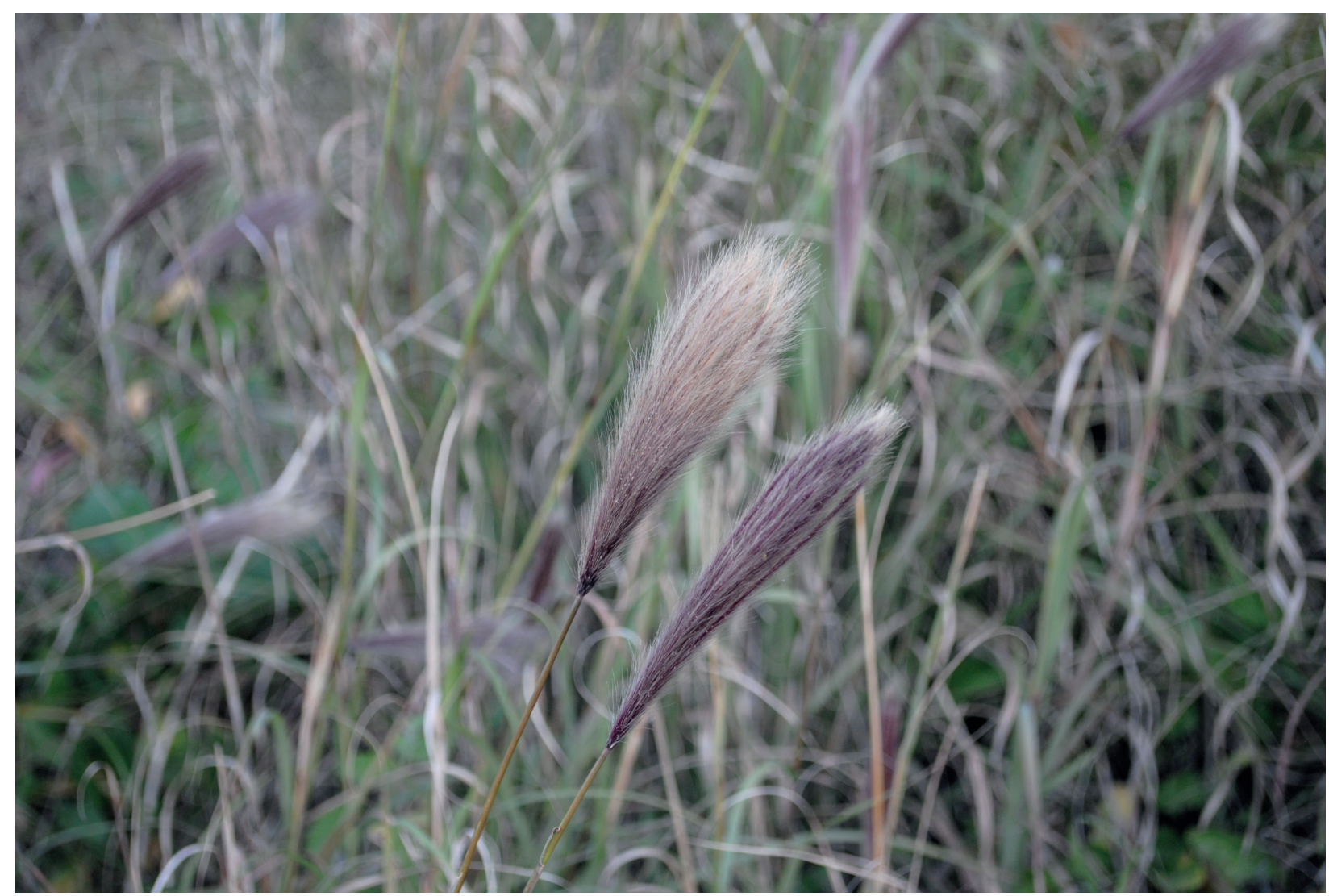

Figura 2. Trichloris crinita (Lag.) Parodi.

situat en un talús de la desembocadura de la riera, DF1882, 15 m, 30.06.2014, H. Álvarez \& C. Gómez (BC 934820, BCN 113528).

No hem trobat cap citació per a la península Ibèrica. A Europa només està indicada per a Grècia (DAISIE, 2013). Està naturalitzada a Austràlia (http:// www.gbif.org) i a la Xina (Zhao et al., 2010).

És una planta dominant en les Grans Planes o praderies seques d'Amèrica del Nord, i que rep el nom comú de buffalo grass per constituir una important pastura pels bisons americans (Hitchcock, 1935).

Es tracta d'una espècie generalment dioica. Els peus masculí i femení tenen un aspecte tan dispar que pot semblar que es tracti de dues espècies diferents. Pot propagar-se amb llavor o vegetativament formant estolons. Té preferència pels sòls alcalins (USDA, 2014). És molt eficient en l'aprofitament de l'aigua i també suporta bé el fred i la calor. És per aquests motius que actualment s'empra en jardineria com a gespa de baix manteniment resistent a la insolació directa i a l'eixut (Monje, 2006).
La població trobada ocupa uns 100-150 $\mathrm{m}^{2}$ d'un talús esclarissat i sec d'exposició sud, amb una inclinació de $30-40^{\circ}$, on és la gespa clarament dominant. Segurament està originada per l'escapament d'individus des d'algun jardí. Hem comprovat que és una zona de pas de ramats d'ovins, factor que potser ha ajudat a la seva dispersió a més distància. Hem recol·lectat plantes d'ambdós sexes, i hem pogut apreciar el dimorfisme sexual de les espigues (Martínez \& Armendáriz, 2010).

Nassella tenuissima (Trin.) Barkworth in Taxon 39: 612 (1990) (Poaceae).

\section{Adventícia.}

Espanya, Barcelona, Baix Llobregat: Viladecans, Camí del Portell Gran, DF1873, 4 m, 14.05.2013, H. Álvarez (BC 878716, BCN 106405).

Gramínia originària de Nou Mèxic, Texas, Mèxic, Xile i Argentina (Connor \& Ford, 1996), naturalitzada a Austràlia, Nova Zelanda, Sud-àfrica i altres parts dels Estats Units. Està considerada una 
espècie invasora (GISD, 2006). A Europa ha estat citada de França (Verloove, 2005a). És emprada com a planta ornamental i el seu ús sembla que s'està estenent per a enjardinar parterres i rotondes de les carreteres (xerojardineria). A Catalunya fins ara es coneixia la presència d'altres espècies del gènere: $N$. neesiana (Trin. \& Rupr.) Barkworth i $N$. trichotoma (Nees) Hack. ex Arechav.

Hem observat una població d'uns $50 \mathrm{~m}^{2}$ situada en un herbassar ruderal sec, a prop de l'estació de tren de Viladecans. La població mostrava signes evidents d'una bona aclimatació i d'una clara tendència expansiva. Hem vist aquesta espècie plantada en un jardí en el nucli urbà de Viladecans, a uns $650 \mathrm{~m}$ de distància de la població naturalitzada.

\section{Novetats a Catalunya}

Atriplex semibaccata $\mathrm{R}$. Br., Prodr. Fl. Nov. Holland: 406 (1810) (Amaranthaceae).

Invasora.

Espanya, Barcelona, Baix Llobregat: Molins de Rei, Riu Llobregat, DF1785, 23 m, 11.07.2013, $H$. Álvarez (BC 878827, BCN 106408); El Papiol, Les Argiles, DF1786, 70 m, 27.10.2013, H. Álvarez (BC 878830).

Camèfit sufruticós d'origen australià introduït a la conca mediterrània com a planta farratgera. Es coneix de llocs salins semiàrids del sud-est de la península Ibèrica i de les illes Canàries des de la dècada dels anys setanta (Sanz-Elorza et al., 2004). També ha estat citat a Saragossa (Mateo \& Pyke, 1997). No apareix recollida ni per Font (2012) ni en estudis recents (Andreu et al., 2012; Andreu \& Pino, 2013). Hem localitzat dues poblacions extenses amb nombrosos exemplars situades entre els termes municipals del Papiol i Molins de Rei. La primera població fa uns dos km de longitud, en disposició paral·lela al riu Llobregat, i forma part d'un herbassar ruderal sec molt trepitjat. La segona, a uns $600 \mathrm{~m}$ de distància de la primera, es troba en els contraforts de la serra de Collserola, en les instal·lacions d'una cantera, sobre terrenys molt denudats i secs, $i$ en els erms adjacents. Els exemplars presenten una tonalitat argentada, amb abundants tiges decumbents arrapades al terra en forma de catifa que poden assolir el metre quadrat de superfície. En la primera data de recol-lecció iniciaven la floració. És una planta que pot trobar-se en fase d'expansió i que està considerada invasora en diferents països (Sanz-Elorza et al., 2004).

Oenothera speciosa Nutt. in J. Acad. Nat. Sci. Philadelphia 2(1): 119 (1821) (Onagraceae).

Naturalitzada.

Espanya, Barcelona, Baix Llobregat: Sant Boi de Llobregat, Muntanya de Sant Ramon, DF1877, 177 m, 21.04.2013, H. Álvarez (BC 878713, BCN 106403); Camí del Bullidor, DF1974, 4,8 m, 06.05.2014, H. Álvarez (BC 934818, BCN 111731).

És originària d'Amèrica del Nord, on viu en praderies $\mathrm{i}$ altres llocs oberts secs. Utilitzada en jardineria per les vistoses flors, i naturalitzada en diferents parts del món (Dietrich, 1997).

La primera cita per a la península Ibèrica correspon a la localitat de Xàtiva (València), en terraplens de la via del ferrocarril (Pau, 1899). No es torna a tenir informació fins a un segle després a València (Ibars \& Estrelles, 2000), a l'antiga llera del riu Túria. Posteriorment ha estat trobada a Màlaga, en dues platges de Torre del Mar (Sanz-Elorza et al., 2002). També ha estat indicada a Badajoz, voltants de Caya (Vázquez et al., 2004), en el campus de la Universitat de Vigo (Gómez et al., 2005, 2006) en terrenys visitats pel bestiar, i a San Vicente de Cerponzones (Pontevedra) en un herbassar que voreja un cultiu d'Eucalyptus globulus Labill.

Hem trobat $O$. speciosa en un aparcament de la muntanya de Sant Ramon, entre un petit mur de pedra i el camí de l'ermita, formant part d'un herbassar ruderal força sec on l'espècie predominant és Hyparrhenia hirta (L.) Stapf. Segons dades del 2013, la població està formada per unes 15 plantes que ocupen uns $3 \mathrm{~m}^{2}$. Recentment hem trobat una segona població més nombrosa en el camí del Bu1lidor. Darrerament hi ha hagut un augment en el nombre d'observacions que pot indicar una tendència expansiva de l'espècie.

Verbena incompta P. W. Michael in Telopea 6: 181 (1995) (Fig. 3) (Verbenaceae).

Naturalitzada.

Espanya, Barcelona, Baix Llobregat: Molins de Rei, Autopista AP-2, DF1785, 30 m, 16.06.2012, H. Álvarez (BC 878310, BCN 100515); ibid., 11.01.2013, H. Álvarez (BC 878718, BCN 106402). 


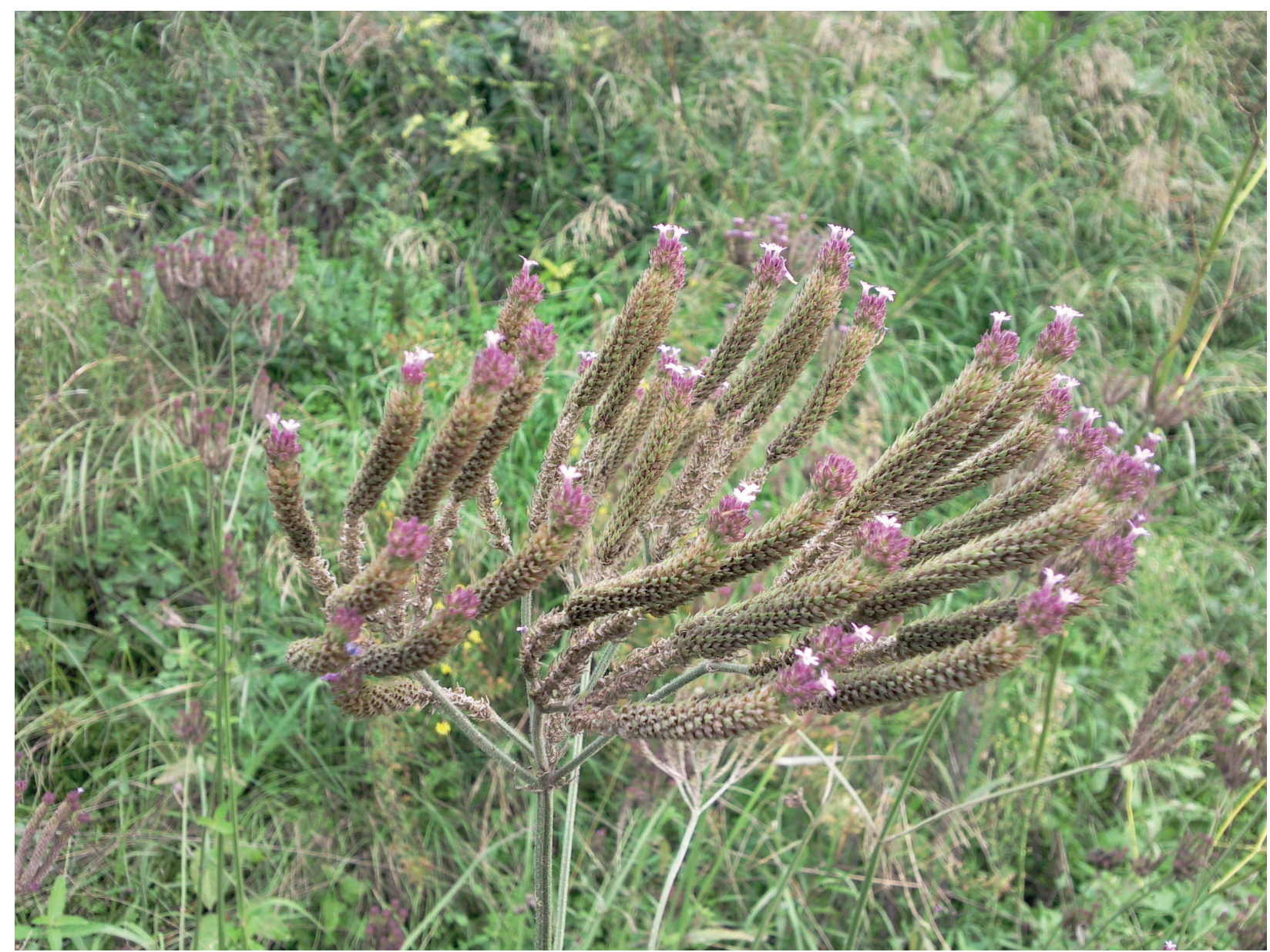

Figura 3. Verbena incompta P. W. Michael.

Verloove (2011) fa referència a unes poblacions trobades a Ligúria (Itàlia) i a Sant Sebastià (Espanya). És una espècie molt similar a $V$. bonariensis L. amb la que sovint ha estat confosa. A diferència d'aquesta espècie, no té interès ornamental i és considerada una mala herba naturalitzada amb un incipient comportament invasor a Itàlia, Portugal, Espanya i Macaronèsia (Verloove, 2011). No ens consten citacions prèvies a Catalunya.

Hem localitzat una densa població formada per uns 500 exemplars en un talús de l'autopista AP-2, que ocupa una superfície d'uns $15 \mathrm{~m}^{2}$. Forma part d'un herbassar ruderal que ressegueix una rasa per on es drena l'aigua de pluja, la qual manté un elevat grau d'humitat edàfica durant bona part de l'any. Amb aquesta planta trobem d'altres al·lòctones com Chloris gayana Kunth i Phalaris stenoptera Hack. amb poblacions abundants. Encara que el conjunt de la població no arriba a superar el metre d'alçada es poden trobar varis exemplars que assoleixen 1,80 m.
Floreix de finals de maig fins a principis de novembre produint unes llargues espigues característiques que poden arribar als $7 \mathrm{~cm}$ de llarg per $5 \mathrm{~mm}$ d'ample.

\section{Novetats comarcals}

Astragalus boeticus L., Sp. Pl.: 758 (1753) (Fig. 4) (Fabaceae).

\section{Naturalitzada.}

Espanya, Barcelona, Baix Llobregat: Viladecans, La Clota DF1775, 33 m, 19.04.2013, H. Álvarez (BC 878717, BCN 106404).

Espècie difosa per les regions Mediterrània, Irano-Turànica i Macaronèsica. Bolòs \& Vigo (1984) esmenten el seu cultiu a petita escala a les Balears, però indiquen que no han pogut comprovar les referències antigues de Catalunya, com ara la deguda a Willkomm \& Lange (1880) qui la consideren naturalitzada als 


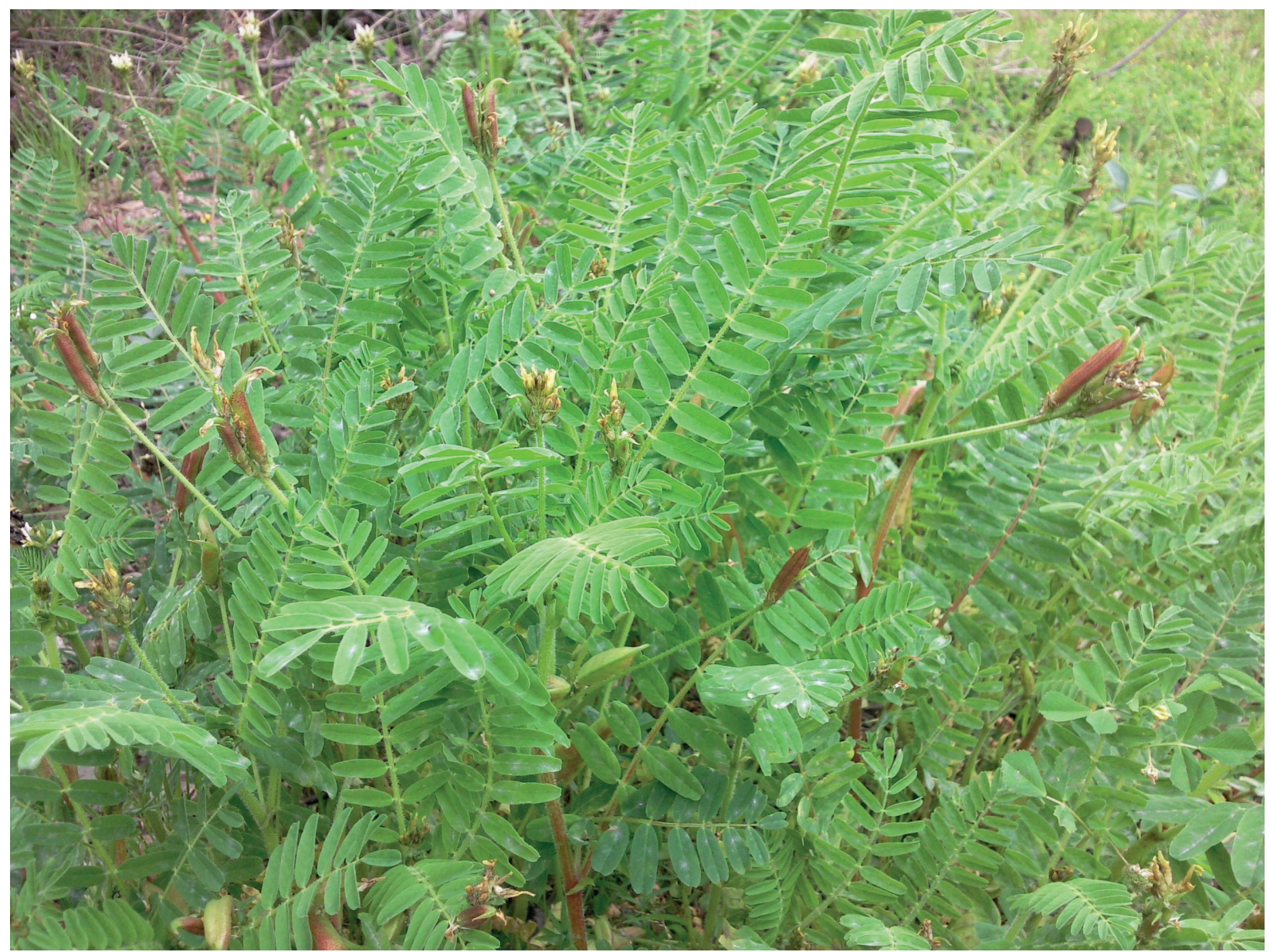

Figura 4. Astragalus boeticus L.

camps de les rodalies de Barcelona, on es podria haver conreat com a substitut del cafè.

Hem localitzat una població que ocupa un camp de cirerers situat al costat de la Riera de Sant Climent de Llobregat. Té una superfície d'uns 3000 $\mathrm{m}^{2}$ i està formada per uns 600 exemplars reproductius. Encara que mostra una bona adaptació, no s'escampa més enllà d'aquest indret on sembla trobar les condicions més favorables.

Parkinsonia aculeata L., Sp. Pl.: 375 (1753) (Fabaceae, subfam. Caesalpinioideae).

Naturalitzada.

Espanya, Barcelona, Baix Llobregat: Sant Boi de Llobregat, Riu Llobregat, DF2077, 8 m, 17.07.2013, H. Álvarez (BC 878824, BCN 106406).

Petit arbre ornamental originari d'Amèrica tropical, introduït a Europa als voltants de 1739 (Bossard
\& Cuisance, 1984). Casasayas (1989) va localitzar aquest tàxon per primer cop a Europa en una riera de les Cases d'Alcanar (Montsià). Actualment es troba naturalitzat en el litoral mediterrani entre les províncies de Màlaga i Tarragona, on afecta de manera especial els ecosistemes fluvials (Sanz-Elorza et al., 2004).

Hem trobat diversos exemplars naturalitzats al llarg de la llera del riu Llobregat entre els termes municipals de Sant Boi de Llobregat i el Prat de Llobregat. Concretament es tracta de cinc petits arbres d'entre 1,8 i 3,5 m d'alçada, que creixen a la part superior de la llera, fora de la zona inundable. Presenten bon estat vegetatiu i tot fa pensar en una clara expansió de la població ja que que disposa de molt espai favorable amb poca competència. Hem observat en diferents punts de la part baixa de la comarca com alguns exemplars comencen a establir-se en marges de carreteres i erms propers a zones enjardinades on han estat 


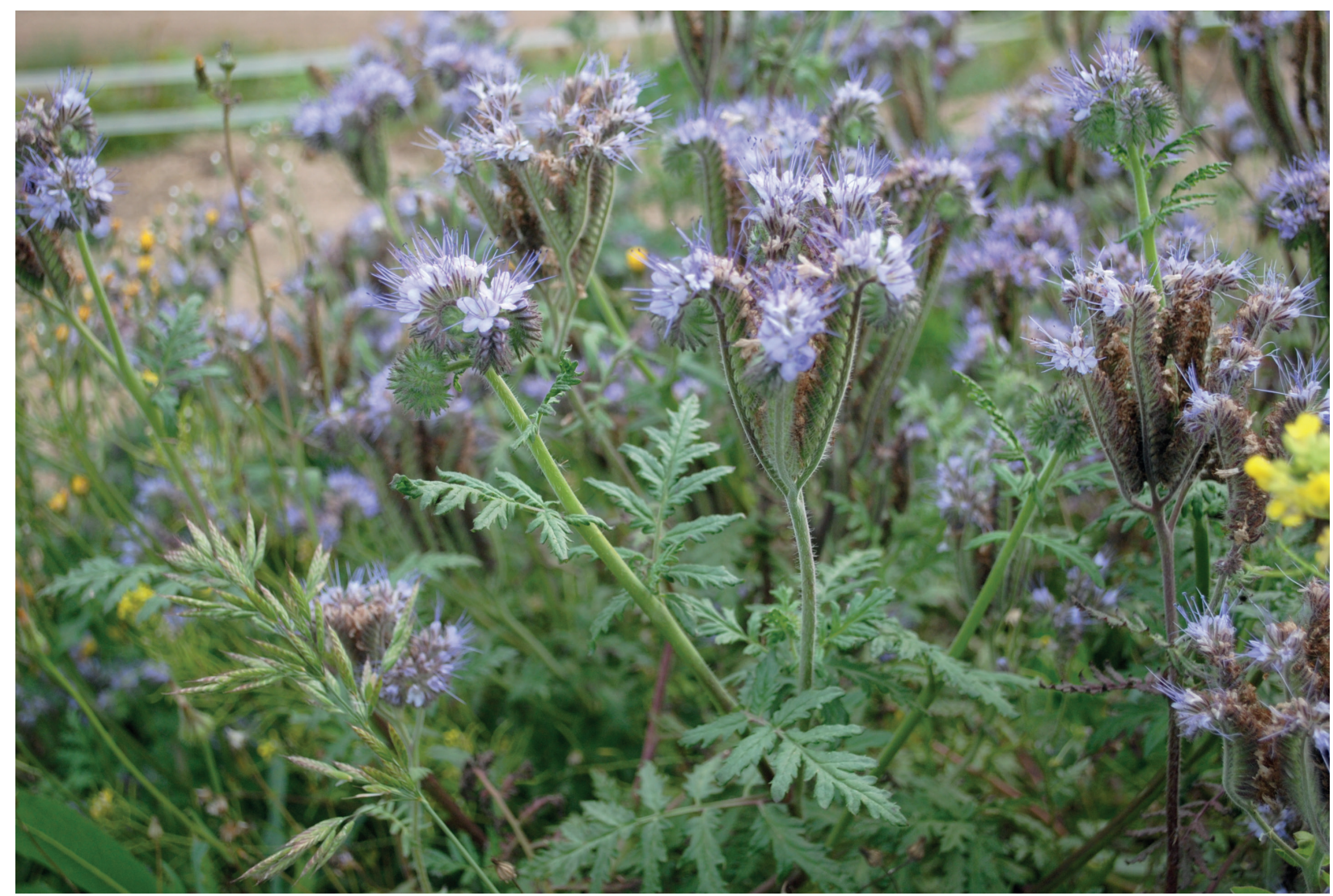

Figura 5. Phacelia tanacetifolia Benth.

plantats, el que ens indica una incipient però clara tendència colonitzadora.

Phacelia tanacetifolia Benth. in Trans. Linn. Soc. London 17(2): 280 (1835) (Fig. 5) (Hydrophyllaceae).

Naturalitzada.

Espanya, Barcelona, Baix Llobregat: Torrelles de Llobregat, Can Reinal, DF1479, 145 m, 18.05.2014, H. Álvarez (BC 934823, BCN 111733).

Espècie originària de l'oest d'Amèrica del Nord, cultivada a regions temperades d'altres continents, on també s'ha naturalitzat. A part de les citacions peninsulars, a Catalunya es coneix de l'Alt Empordà, del Priorat (Sáez et al., 2000), del Montsià (Cardero et al., 2004) i de la Garrotxa (Béjar, 2008; Oliver et al., 2009).

Phacelia tanacetifolia es fa servir com a planta mel·lífera, tant a Amèrica com a Europa i també es cultiva amb finalitat ornamental i farratgera. Hi han estudis per utilitzar-la en la recuperació de coberta vegetal a àrees pertorbades $\mathrm{i}$ de terrenys pobres $(\mathrm{Ky}-$ riazopoulos et al., 2012) i s'ha fet servir per a revegetació de pistes i talussos (Aparicio, 2008).

Viu en herbassars ruderals i vores de camins, creix bé a diferents tipus de sòls, encara que s'adapta millor als terrenys ben drenats de regions baixes. L'hem trobada en una petita vall de muntanya, en exposició nord, escampada al llarg d'uns marges entre bancals conreats, formant part d'un herbassar arvense.

Physalis peruviana L., Sp. Pl. ed. 2. 2: 1670 (1763) (Fig. 6) (Solanaceae).

Adventícia a Catalunya.

Espanya, Barcelona, Baix Llobregat: Sant Climent de Llobregat, Camí a Torrelles de Llobregat, DF1577, 132 m, 22.10.2012, H. Álvarez (BC 878309, BCN 100516); Abrera, Torrent Gran d'Abrera, DF0696, 130 m, 30.09.2012, H. Álvarez (BC 878712, BCN 100563); Viladecans, Riera de Sant Llorenç, DF1873, 5 m, 06.10.2013, H. Álvarez (BC 878829). 


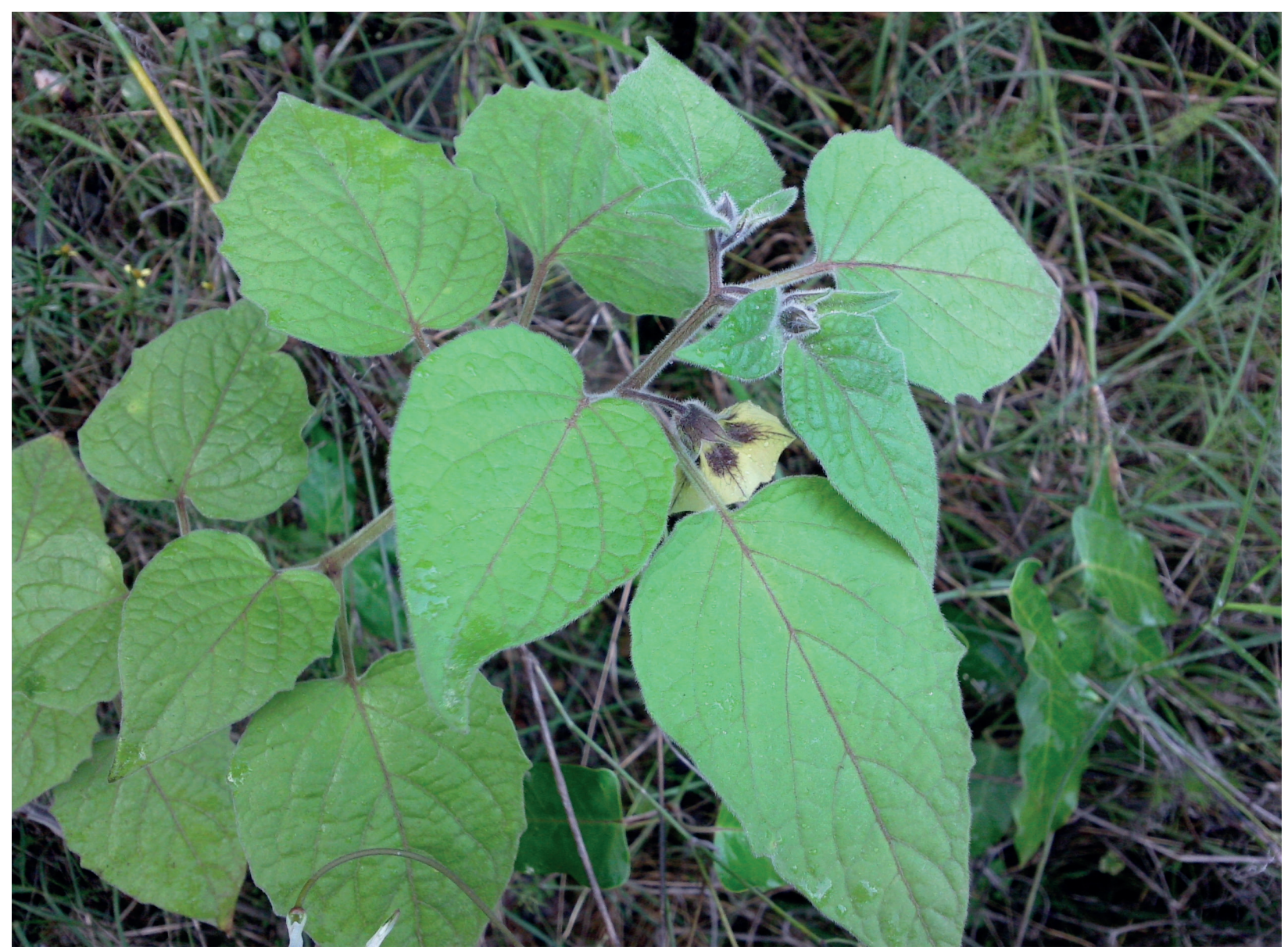

Figura 6. Physalis peruviana L.

És originària dels Andes peruans, d'Equador i Colòmbia (Medina, 1991). Viu en zones tropicals i subtropicals entre els 1500 i els 3000 m (Villamizar et al., 1993). Ha estat introduïda en diversos països de clima temperat per aprofitar el seu fruit comestible.

A Catalunya es coneix la seva presència per Costa (1877) que la cita com a rara prop de Barcelona, i d'un plec recol·lectat a Cambrils per Sennen el 1909 (BC 906380). Casasayas (1989) la considera una espècie adventícia, en no ser retrobada. La citació més recent és la d'un exemplar trobat en un marge d'hort del Baix Empordà, a Fonteta, municipi de Forallac (Aymerich, 2014). També es troba en diferents punts de la península Ibèrica i les illes Balears, principalment en àrees costaneres mediterrànies (Sanz-Elorza \& Sobrino, 2012).

Hem localitzat tres poblacions situades en entorns naturals poc o molt alterats amb elevada humitat. $\mathrm{La}$ primera es troba en un herbassar subnitròfil localitzat en un petit torrent tributari de la riera de Can Carreres vora la pista forestal de Torrelles de Llobregat. Són cinc exemplars fructífers d'uns $60 \mathrm{~cm}$ d'alçada. El segon grup d'exemplars es troba en el torrent Gran d'Abrera en vegetació de ribera ben conservada. Els cinc exemplars superen el metre d'alçada i també han pogut fructificar, però s'han vist afectats per una glaçada. El tercer grup esta format per un gran exemplar de 1,2 $\mathrm{m}$ d'alçada situat en el talús de la riera de Sant Llorenç. És possible que la presència d'aquesta espècie augmenti degut a un creixent consum dels seus fruits. L'hem observada plantada en diferents horts de la comarca.

Salpichroa origanifolia (Lam.) Baill., Hist. P1. 9: 288 (1888) (Fig. 7) (Solanaceae).

\section{Naturalitzada.}

Espanya, Barcelona, Baix Llobregat: Sant Boi del Llobregat, nus viari entre les carreteres C-245 i C-32, DF2077, 12 m, 22.10.2014, H. Álvarez (BC 879593, BCN 117984). 


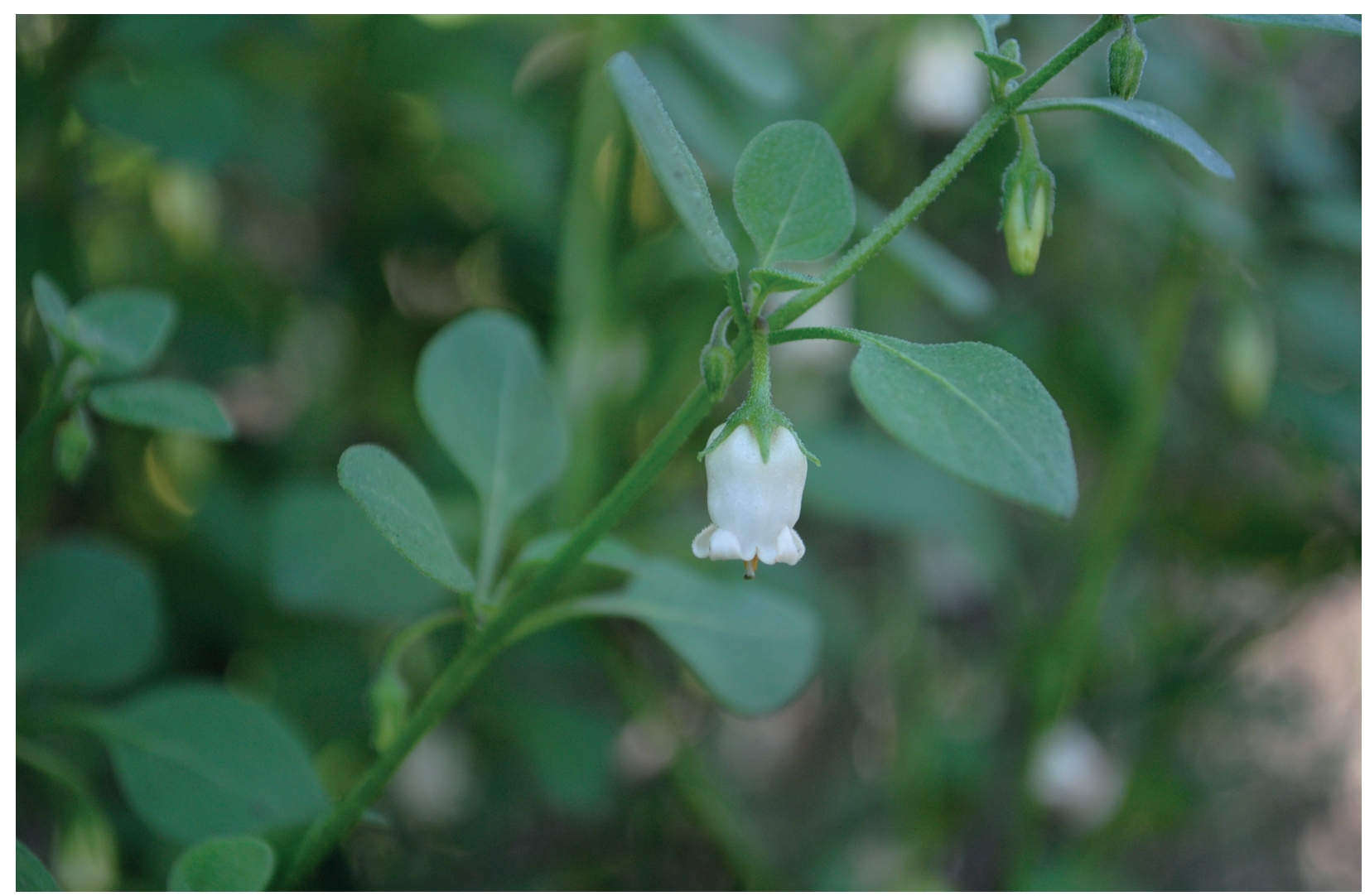

Figura 7. Salpichroa origanifolia (Lam.) Baill.

És originària de les zones baixes i temperades de l'Amèrica del Sud. Se li atribueixen propietats antiinflamatòries $i$ analgèsiques, sense produir efectes secundaris gàstrics, $\mathrm{i}$ també pel guariment dels penellons i algunes afeccions de la pell (Boeris et al., 2004). Va ser introduïda a Europa al segle XIX pels seus fruïts comestibles i com a planta mel·lífera (Casasayas, 1989). Font i Quer (1926) i Bolòs (1950) ja van fer referència a aquest tàxon a Catalunya com a $S$. rhomboidea (Gillies \& Hook.) Miers. Casasayas (1989) va considerar aquesta planta en expansió a la zona de Barcelona. Ara sembla en regressió o, com a mínim, no ha augmentat la seva distribució. De fet, a Catalunya només ha estat citada de Roses i de la zona del Barcelonès (Bolòs et al., 2003).

A Catalunya $S$. origanifolia creix en ambients alterats i més aviat humits. De fet la vam trobar en un herbassar ruderal humit, a prop d'una illeta de circumval-lació del trànsit, formant una població d'uns $100 \mathrm{~m}^{2}$.

Verbena brasiliensis Vell., F1. Flumin. 1: t. 40, 17 (1829) (Verbenaceae).
Naturalitzada.

Espanya, Barcelona, Baix Llobregat: Molins de Rei, riu Llobregat, DF1785, 20 m, 12.01.2014, H. Álvarez; Sant Boi de Llobregat, riu Llobregat, DF2177, 3,7 m, 20.01.2014, H. Álvarez (BC 878853); El Prat de Llobregat, riu Llobregat, DF2277, 3,8 m, 03.02.2014, H. Álvarez (BC 878854); Sant Boi de Llobregat, riu Llobregat, DF2177, 3,7 m, 25.06.2014, H. Álvarez (BC 934819, BCN 113529).

És originària d'Amèrica del Sud, però s'escampa fins al nord i cap a la resta de continents. A Europa s'ha indicat de la península Ibèrica, Itàlia $\mathrm{i}$ Gran Bretanya (ISC, 2014). Verloove (2003) la va trobar a la Tordera (Barcelona) i Hostalric (Girona). Posteriorment, aquest autor la va trobar a Sant Celoni, Gualba de Baix i la Batllòria, i indica que totes les $V$. litoralis que ha vist pertanyen a la varietat brasiliensis (Verloove, 2005b).

Encara no hi ha una posició generalitzada sobre la nomenclatura d'aquesta planta. Com apunta Verloove (2003), segons alguns autors es tracta d'una varietat de $V$. litoralis, i segons altres és una espècie amb entitat pròpia. El que sembla clar és que es tracta d'un 
tàxon diferent de $V$. litoralis. De fet, Nesom (2010) considera a $V$. brasiliensis dins de la sèrie Pachystachyae Schauer in DC. - d'espigues fructíferes relativament curtes i amples, amb denses formacions de fruits sèssils o subsèssils que es superposen entre ells- i a V. litoralis com a tipus de la sèrie Litorales Nesom, d'espigues més llargues i esveltes amb fruits pedunculats. Nosaltres fem servir el nom de $V$. brasiliensis d'acord amb el criteri de Govaerts (2014).

Hem localitzat diferents poblacions situades al 1 lit del riu, en zones periòdicament inundades per les avingudes, sobre petits monticles formats pels llots i altres materials arrossegats per l'aigua. Arriben a una alçada d'entre 1,50 i $2,50 \mathrm{~m}$, i creixen formant agrupacions molt compactes que ocupen superfícies de pocs metres quadrats.

\section{Rares a Catalunya}

Abutilon grandifolium (Willd.) Sweet in Hort. Brit. 1: 53 (1826) (Malvaceae).

Naturalitzada.

Espanya, Barcelona, Baix Llobregat: Sant Boi de Llobregat, Camí del Bullidor, DF1974, 6 m, 17.02.2013, H. Álvarez (BC 878715, BCN 106359).

Malvàcia arbustiva originària d'Amèrica del Sud que ha estat conreada com a ornamental i per extreure'n la fibra vegetal. Introduïda en diferents parts càlides del món. A la península Ibèrica es coneix de les rodalies de Cadis escapada de cultiu (Paiva \& Nogueira, 1999). A Catalunya només ha estat citada de La Ricarda, el Prat de Llobregat (Verloove \& Sánchez-Gullón, 2008). Nosaltres hem localitzat una població situada en el talús de l'autopista C-32 al Camí del Bullidor, formant part d'un dens herbassar ruderal força càlid orientat al sud. Aquesta petita població està formada per les restes ja seques d'un gran exemplar d'uns dos metres d'alçada i per un grup d'exemplars joves en flor que creixen al seu voltant. Els exemplars estan sotmesos a la sega periòdica del voral de l'autopista.

Asperugo procumbens L., Sp. P1.: 138 (1753) (Boraginaceae).

Naturalitzada.

Espanya, Barcelona, Baix Llobregat: Viladecans, Depuradora d'Aigües, DF1969, 1 m, 09.04.2013, H. Álvarez (BC 878714, BCN 106401).
Tàxon possiblement nou per a la comarca del Baix Llobregat. Aquesta espècie és citada d'antic de les rodalies de Barcelona (Colmeiro, 1846) i per nombrosos botànics que l'esmenten de Montserrat, a les rodalies de l'abadia i els seus horts, sempre lligada amb activitats humanes. En l'actualitat no ha estat retrobada a Montserrat (Nuet \& Panareda, 1991: 123). Casasayas (1989) la considera un arqueòfit procedent del nord, est i centre-est d'Europa, introduït d'antic a la península Ibèrica, naturalitzat en indrets frescals ruderalitzats sovint a prop de llocs amb bestiar. És una planta montana poc freqüent a terra baixa i molt rara a la línia de la costa.

Hem localitzat una població nombrosa i compacta (uns 500 exemplars que ocupen una superfície aproximada d'uns $30 \mathrm{~m}^{2}$ ), formant part d'un herbassar nitròfil sobre terreny sorrenc, que s'estén entre el marge d'un camp d'oliveres i la corredora de les Sorres-Censat, a tocar de les instal-lacions de la depuradora d'aigües de Gavà-Viladecans.

Eclipta prostrata (L.) L., Mantissa Alt.: 286 (1771) (Fig. 8) (Asteraceae).

Naturalitzada.

Espanya, Barcelona, Baix Llobregat: El Papiol, Canal de la Infanta, DF1687, $30 \mathrm{~m}, 17.08 .2013, H$. Álvarez (BC 878828, BCN 106409).

Asteràcia neotropical considerada una mala herba cosmopolita (D'Arcy, 1975) que viu en indrets humits sovint associada al conreu de l'arròs, formant part d'herbassars higronitròfils. La primera cita per a Catalunya és del 1893 (Vayreda, 1902) al Riu Francolí. Posteriorment és descoberta a la desembocadura del delta del Llobregat per Segura (1952). Segons Bolòs \& Vigo (1996) probablement es troba extingida en aquestes localitats. També és present al delta de l'Ebre (Bolòs \& Masclans, 1955), Lleida (Bolòs \& Vigo, 1979), Sant Pere Pescador (Casasayas, 1989) i a Vilanova de Sau (Batriu et al., 2012).

La nostra localització és la segona per a la comarca, i està ubicada al canal de la Infanta prop de la riera de Rubí. Eclipta prostrata forma una població atapeïda d'uns dos metres quadrats, acompanyada per Polygonum persicaria L. i Lycopus europaeus L. Els exemplars es troben en plena floració $i$ arriben als $90 \mathrm{~cm}$ de longitud. 


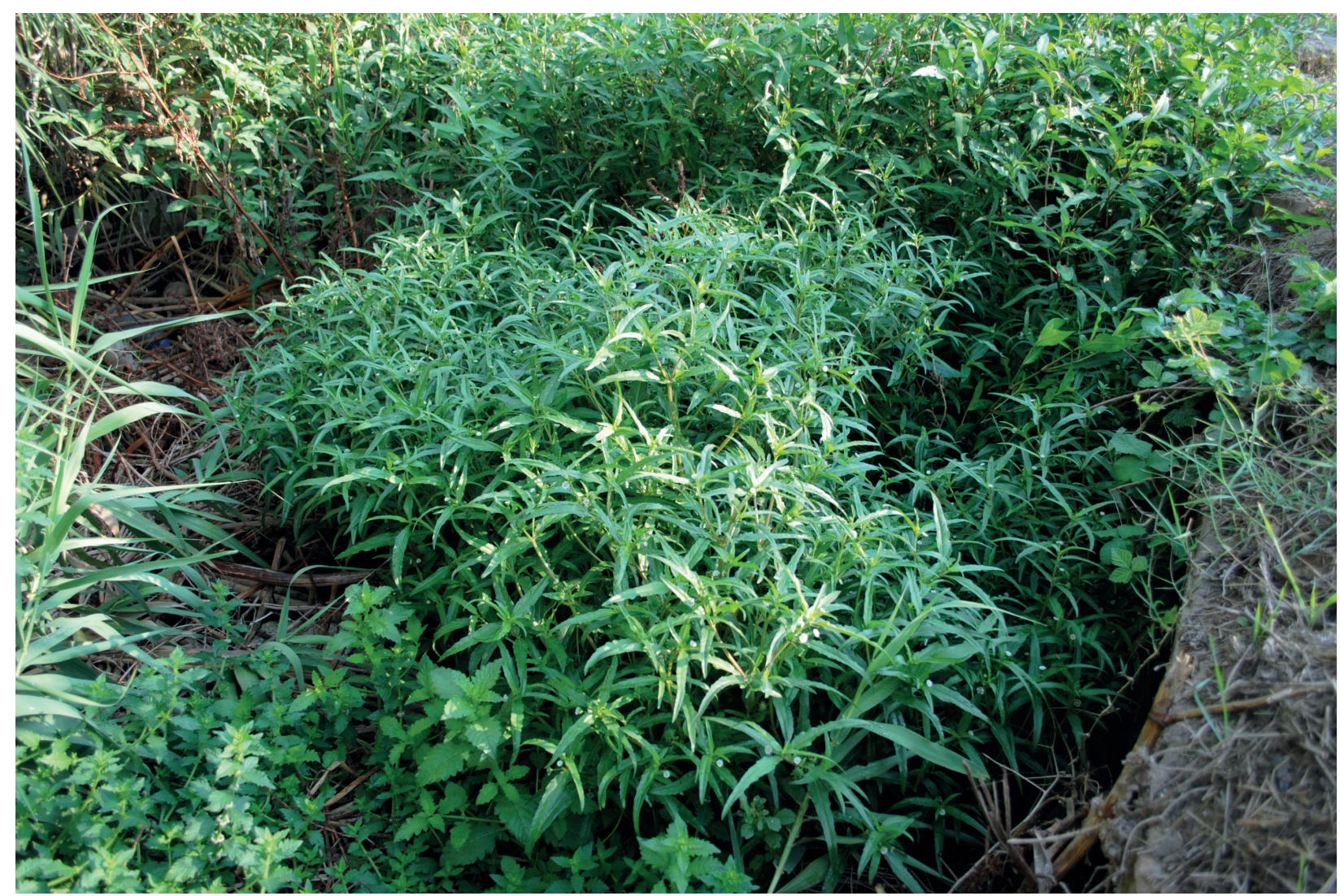

Figura 8. Eclipta prostrata (L.) L.

Oenothera indecora Cambess., Fl. Bras. Merid. (quarto ed.) 2(17): 268 (1830) (Fig. 9) (Onagraceae).

Naturalitzada.

Espanya, Barcelona, Baix Llobregat: Castelldefels, La Pava, DF1569, 1,6 m, 22.06.2013, H. Álvarez (BC 878825, BC 878826); ibid., 20.06.2014, H. Álvarez (BCN 113526); Platja de Covafumada, DF1168, 1 m, 08.08.2011, H. Álvarez (herb. pers.).

És una planta nativa d'Amèrica del Sud (Dietrich, 1977). A Europa està naturalitzada a Portugal (Rostanski, 1991) i a Grècia (Raus, 2006). Aquest darrer autor la considera en expansió a la regió mediterrània. Recentment ha estat trobada a la part marítima del municipi de Gavà (Barcelona) - possiblement desapareguda - i a Huelva (Moguer) (Verloove \& Sánchez-Gullón, 2008, 2012).

Hem localitzat dues noves poblacions a Castelldefels, una situada al paratge de La Pava al costat del Canal Olímpic, formada per una cinquantena de plantes de bona mida i amb bon estat vegetatiu, creixent sobre un terreny sorrenc i dins d'un herbassar ruderal sec. La segona població, de pocs exemplars, es troba a la platja de Covafumada sobre la rereduna a pocs metres del passeig marítim. En les dues poblacions els exemplars han aconseguit fructificar i produir bon nombre de llavors. Disposa d'àrees favorables per incrementar les seves poblacions en el futur, probablement en expansió.

\section{AGRAÏMENTS}

Els autors volem expressar el nostre agraïment a en S. Pyke (Jardí Botànic de Barcelona) pels seus valuosos comentaris, en especial per ajudar-nos amb la determinació d'Acacia rostellifera. Agraïm també al suport del projecte 2014SGR514. Donem les gràcies al revisor del text per les seves aportacions.

\section{REFERÈNCIES BIBLIOGRÀFIQUES}

Andreu, J. \& Pino, J. 2013. El projecte EXOCAT. Informe 2013. Departament d'Agricultura, Ramaderia, Pesca, Alimentació i Medi Natural (Generalitat de Catalunya), Barcelona. 


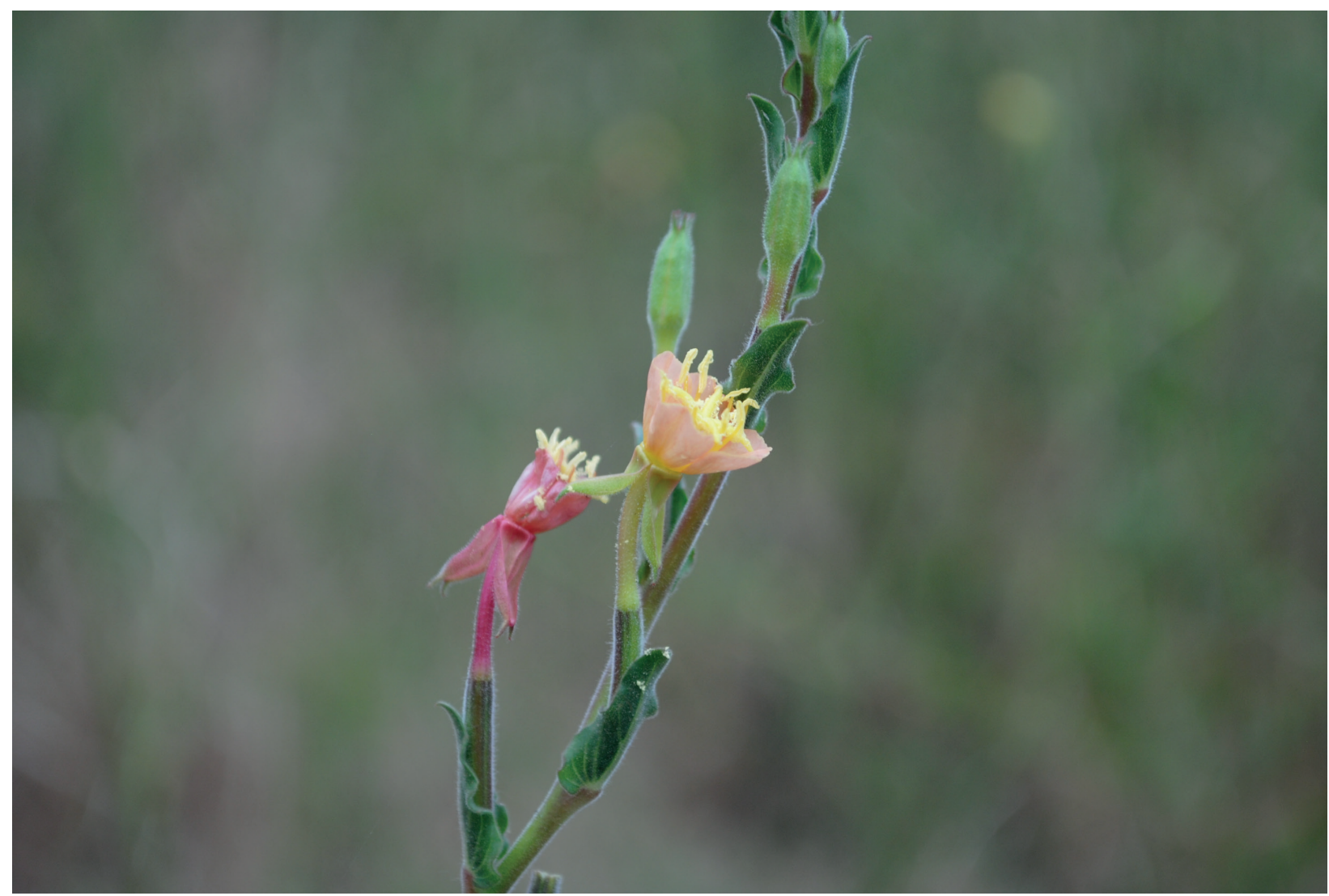

Figura 9. Oenothera indecora Cambess.

Andreu, J., Pino, J., Basnou, C., Guardiola, M. \& Ordóñez, J. L. 2012. Resum del projecte EXOCAT 2012. Departament d'Agricultura, Ramaderia, Pesca, Alimentació i Medi Natural (Generalitat de Catalunya), Barcelona.

Aparicio, J. M. 2008. Aportaciones a la flora de la provincia de Castellón, XII. Toll Negre 10: 81-94.

Aymerich, P. 2014. Notes florístiques de les conques altes dels rius Segre i Llobregat (II). Orsis 28: 7-47.

Batriu, E., Blanco-Moreno, J. M., Mercadé, A. \& Pérez-Haase, A. 2012. Aportació al coneixement florístic de les Guilleries i del Collsacabra (Catalunya Oriental), III. Butlletí de la Institució Catalana d'Història Natural 76: 147-157.

Béjar, X. 2008. Lacy phacelia (Phacelia tanacetifolia). iNaturalist.org. California Academy of Sciences, San Francisco. Consultat el 30 d'octubre de 2014, a http://www. inaturalist.org/observations/180873 [citat amb permís del autor]

Boeris, M. A., Toso, R. E. \& Skliar, M. I. 2004. Actividad antiinflamatoria de Salpichroa origanifolia. Acta Farmacéutica Bonaerense 23: 138-141.

Bolòs, A. de 1950. Vegetación de las comarcas Barcelonesas. Instituto Español de Estudios Mediterráneos, Barcelona.

Bolòs, O. de, Font, X. \& Vigo, J. (Eds.) 2003. Atlas Corològic de la flora vascular dels Països Catalans 12 (ORCA, Atlas Coròlogic, 12). Secció de Ciències Biològiques (Institut d'Estudis Catalans), Barcelona.

Bolòs, O. de \& Masclans, F. 1955. La vegetación de los arrozales en la región mediterránea. Collectanea Botanica (Barcelona) 4: 415-434.
Bolòs, O. de \& Vigo, J. 1979. Observacions sobre la flora dels Països Catalans. Collectanea Botanica (Barcelona) 11: 25-89.

Bolòs, O. de \& Vigo, J. 1984. Flora dels Països Catalans 1. Barcino, Barcelona.

Bolòs, O. de \& Vigo, J. 1996. Flora dels Països Catalans 3. Barcino, Barcelona.

Bossard, R. \& Cuisance, P. 1984. Arbres et arbustes d'ornement des régions temperées et Méditerranéennes. Technique \& Documentation Lavoisier, Paris.

Cardero, S., Royo, F. \& Torres, L. de 2004. Novetats florístiques per a les Terres de l'Ebre. Butlletí de la Institució Catalana d'Història Natural 72: 99-103.

Casasayas, T. 1989. La flora al-lòctona de Catalunya: Catàleg raonat de les plantes vasculars exòtiques que creixen sense cultiu al NE de la Península Ibèrica. Tesi Doctoral, Universitat de Barcelona, Barcelona.

Colmeiro, M. 1846. Catálogo metódico de plantas observadas en Cataluña. Librería de la señora viuda e hijos de Don Antonio Calleja, Madrid.

Connor, H. E. \& Ford, K. 1996. Stipa tenuissima, and name changes in stipoid grasses. Weed Identification News 20: $1-5$.

Costa, A. C. 1877. Introducción a la Flora de Cataluña y catálogo razonado de las plantas observadas en esta región (2a ed.). Imprenta Diario de Barcelona, Barcelona.

DAISIE (European Invasive Alien Species Gateway) 2013. Acacia ligulata, Trichloris crinita. Consultat l'octubre de 2013, a http://www.europe-aliens.org/ 
D’Arcy, W. G. 1975. Compositae. Flora of Panama. Annals of Missouri Botanical Garden 62: 1101-1173.

Dietrich, W. 1977. The South American species of Oenothera sect. Oenothera (Raimannia, Renneria; Onagraceae). Annals of Missouri Botanical Garden 64: 425-626. http:// dx.doi.org/10.2307/2395257

Dietrich, W. 1997. Oenothera L. In: Castroviejo, S., Aedo, C., Benedí, C. et al. (Eds.), Flora iberica 8. Real Jardín Botánico (CSIC), Madrid: 91-100.

Font i Quer, P. 1926. De flora occidentale adnotationes. Butlletí de la Institució Catalana d'Història Natural 7: 53-57.

Font, X. 2012. Mòdul Flora i Vegetació. Banc de Dades de Biodiversitat de Catalunya. Generalitat de Catalunya \& Universitat de Barcelona, Barcelona. Consultat d'octubre de 2013 a gener de 2015, a http://biodiver.bio.ub.es/biocat/index.jsp

Giorgetti, H. D., Montenegro, O. A., Rodríguez, G. D. et al. 1997. The comparative influence of past management and rainfall on range herbaceous standing crop in east-central Argentina: 14 years of observations. Journal of Arid Environments 36: 623-637. http://dx.doi.org/10.1006/ jare.1996.0220

GISD (Global Invasive Species Database) 2006. Consultat d'octubre de 2013 a gener de 2015, a http://www.issg.org/database

Gómez, F., García, X. R., Pino, R. et al. 2005. Aportaciones a la flora de Galicia, VII. Nova Acta Científica Compostelana (Bioloxía) 14: 57-68.

Gómez, F., García, X. R., Silva-Pando, F. et al. 2006. Aportaciones a la flora de Galicia, VIII. Nova Acta Científica Compostelana (Bioloxía) 15: 53-63.

Govaerts, R. 2014. World Checklist of Selected Plant Families (WCSPF). Royal Botanic Gardens, Kew. Consultat d'octubre de 2013 a gener de 2015, a http://apps.kew.org/wcsp/ namedetail.do?name id $=212136$

Hitchcock, A. S. 1935. Manual of the grasses of the United States (United States Department of Agriculture - Miscellaneous Publication, 200). United States Department of Agriculture, Washington, DC.

Ibars, A. M. \& Estrelles, E. 2000. Una nueva localidad de Oenothera speciosa Nutt. para la Península Ibérica. Flora Montiberica 16: 25-26.

Ibáñez, N. 2006. Estudis sobre cinc herbaris històrics de l'Institut Botànic de Barcelona. Tesi Doctoral, Universitat de Barcelona, Barcelona.

ILDIS (International Legume Database \& Information Service) 2013. Consultat el 29 de octubre de 2014, a http://www. ildis.org

IPNI (The International Plant Names Index) 2012. Consultat el 10 de desembre de 2014, a http://www.ipni.org

ISC (Invasive Species Compendium) 2014. Verbena brasiliensis - Datasheet. CABI Publishing, Wallingford. Consultat el 12 de novembre de 2014, a http://www.cabi.org/isc/datasheet $/ 117790$

Kyriazopoulos, A. P., Abraham, E. M., Parissi, Z. M. \& Tsiouvaras, C. 2012. Evaluation of different herbaceous species used for revegetation of a limestone quarry with a thin topsoil layer in the Mediterranean region. Journal of Food, Agriculture \& Environment 10: 1152-1155.

Martínez, J. M. \& Amendáriz, S. 2010. Bases morfológicas de cómo pudo haberse originado el dimorfismo sexual en el pasto búfalo. Revista Fitotecnia Mexicana 33: 69-73.

Mateo, G. \& Pyke, S. 1997. Aportaciones a la flora cesaraugustana, IV. Flora Montiberica 5: 50-52.

Medina, M. 1991. El cultivo de la uchuva tipo exportación. Revista Agricultura Tropical 28: 55-58.
Monje, R. J. 2006. Manejo de céspedes con bajo consumo de agua ( $2^{\mathrm{a}}$ ed). Consejería de Agricultura y Pesca (Junta de Andalucía), Sevilla.

Nesom, G. L. 2010. Infrageneric classification of Verbena (Verbenaceae). Phytoneuron 2010-11: 1-15.

Nuet, J. \& Panareda, J. M. 1991. Flora de Montserrat 2. Publicacions de l'Abadia de Montserrat, Barcelona.

Oliver, X., Béjar, X., Lockwood, M. et al. 2009. Aportacions al coneixement de la flora vascular de la Garrotxa i comarques veïnes. Butlletí de la Instució Catalana de Història Natural 75: $146-152$.

Paiva, J. J. \& Nogueira, L. I. 1999. Abutilon Mill. In: Castroviejo, S., Aedo, C., Cirujano, S. et al. (Eds.), Flora iberica 3. Real Jardín Botánico (CSIC). Madrid: 202-203.

Parodi, L. R. 1919. Las Chlorideas de la República Argentina. Revista de la Facultad de Agronomía y Veterinaria 2: 233-340.

Pau, C. 1899. La Oenothera speciosa en España. Actas de la Sociedad Española de Historia Natural 28: 212-213.

Peterson, P. M. 2001. Trichloris. In: Soreng, R. J., Davidse. G., Filgueiras, T. S. \& Zuloaga, F. O. \& Judziewicz, E. J. (Eds.), Catalogue of New World Grasses (Poaceae): II. Subfamily Chloridoideae (Contributions from the United States National Herbarium, 41). Department of Systematic Biology - Botany (National Museum of Natural History), Washington, DC: 222-223.

Raus, T. 2006. Oenothera indecora subsp. indecora. In: Greuter, W. \& Raus, T. (Eds.), Med-Checklist Notulae, 24. Willdenowia 36: 724-725.

Rostanski, K. 1991. The representatives of the genus Oenothera L. in Portugal. Boletim da Sociedade Broteriana 64: 5-33.

Sáez, L., Carrillo, E., Mayol, M., Molero, J. \& Vallverdú, J. 2000. Noves aportacions a la flora de les comarques meridionals de Catalunya. Acta Botanica Barcinonensia, 46: 97-118.

Sanz-Elorza, M., Dana, E. D. \& Sobrino, E. 2004. Atlas de las plantas alóctonas invasoras en España. Dirección General para la Biodiversidad (Ministerio de Medio Ambiente), Madrid.

Sanz-Elorza, M. \& Sobrino, E. 2012. Physalis L. In: Castroviejo, S., Aedo, C., Aguiar, C. et al. (Eds.), Flora iberica 11. Real Jardín Botánico (CSIC). Madrid: 204-205.

Sanz-Elorza, M., Sobrino, E. \& Dana, E. D. 2002. Oenothera speciosa (Onagraceae), reaparece en España (Andalucía) después de un siglo. Lagascalia 22: 157-159.

Segura, A. 1952. Nota sobre cuatro especies adventicias halladas en los arrozales del delta del Llobregat. Collectanea Botanica (Barcelona) 3: 169-173.

Stevens, P. F. (2001-). Angiosperm Phylogeny Website (Version 12, July 2012). Consultat el 4 de novembre de 2014, a: http://www.mobot.org/MOBOT/research/APweb/

Tutin, T. G., Heywood, V. H., Burgues, N. A. et al. (Eds.) 1980. Flora Europaea 5. Alismataceae to Orchidaceae (Monocotyledones). Cambridge University Press, Cambridge.

USDA (United States Department of Agriculture) 2014. Bouteloua dactyloides (Nutt.) J.T. Columbus - buffalograss. The PLANTS Database. National Plant Data Team, Greensboro. Consultat el 18 d'octubre de 2014, a: http://plants. usda.gov/core/profile?symbol=BODA2

Vayreda, E. 1902. Plantas de Cataluña. Anales de la Sociedad Española de Historia Natural (Ser. 2) 10(30): 491-582.

Vázquez, M., Ramos, S., Lucas, A. B., García, D. \& Blanco, J. 2004. Aportaciones a la flora de Extremadura (España). Acta Botanica Malacitana 29: 265-268. 
Verloove, F. 2003. Physalis ixocarpa Brot. ex Hornem. and Verbena litoralis Kunth, new Spanish xenophytes and records of other interesting alien vascular plants in Catalonia (Spain). Lazaroa 24: 7-11.

Verloove, F. 2005a. A synopsis of Jarava Ruiz \& Pav. and Nassella E. Desv. (Stipa L. s.1.) (Poaceae: Stipeae) in southwestern Europe. Candollea 60: 97-117.

Verloove, F. 2005b. New records of interesting xenophytes in Spain. Lazaroa 26: 141-148.

Verloove, F. 2011. Verbena incompta (Verbenaceae), an overlooked xenophyte in Europe. Willdenowia 41: 43-49. http://dx. doi.org/10.3372/wi.41.41104

Verloove, F. \& Sánchez-Gullón, E. 2008. New records of interesting xenophytes in the Iberian Peninsula. Acta Botanica Malacitana 33: 147-167.
Verloove, F. \& Sánchez-Gullón, E. 2012. New records of interesting vascular plants (mainly xenophytes) in the Iberian Peninsula II. Flora Mediterranea 22: 5-24. http://dx.doi. org/10.7320/FlMedit22.005

Villamizar, F., Ramírez, A. \& Menes, M. 1993. Estudio de la caracterización física, morfológica y fisiólogica poscosecha de la uchuva (Physalis peruviana L.). Agrodesarrollo 4: 305-320.

Willkomm, M. \& Lange, J. 1880. Prodomus Florae Hispanicae 3. Sumtibus E. Schweizerbart (E. Koch), Stuttgart.

Zhao, J., Ouyang, Z., Zheng, H., Xu, W., Wang, X. \& Ni, Y. 2010. 北京建成区外来植物的种类构成 [Species composition of alien plants in the built-up area of Beijing]. Biodiversity Science 18: 19-28 [in Chinese]. 